\title{
Pandemia como laboratório de poder
}

Pandemic as a laboratory of power

Marco Antônio Sousa Alves²

Resumo: Crises sanitárias constituem momentos propícios para a experimentação de novas tecnologias de poder. Nesses contextos, velhas práticas de governo são colocadas em suspenso e, em caráter inicialmente emergencial e excepcional, novas táticas de controle e organização social são ensaiadas. O estudo desenvolvido neste artigo toma por base a análise empreendida por Foucault ao longo dos anos 1970, que distinguiu três ensaios nesse sentido, quais sejam, o modelo da lepra, da peste e da varíola, que estão associados a diferentes mecanismos de poder, de tipo soberano-legal, disciplinar e biopolítico ou securitário, respectivamente. Após uma apresentação da contribuição foucaultiana, ○ artigo procura traçar uma linha de atualização, dando prosseguimento ao projeto de uma analítica do poder. $O$ foco é então direcionando para o novo modelo da COVID-19 que emerge no presente, marcado pela datificação da vida, pelo uso de big data, pela vigilância ubíqua e pelo governo algorítmico, no seio de um grande sonho tecnocrático, de uma sociedade digitalizada, controlada e gerida eficientemente.

Palavras-chave: pandemia; Foucault; poder; modelo da COVID-19.

Abstract: Sanitary crises are propitious moments for the experimentation of new technologies of power. In these contexts, old governance practices are put on hold and, in an emergency and exceptional character, new tactics of control and social organization are tested. The study developed in this article is based on the analysis undertaken by Foucault throughout the 1970s. He distinguished three answers: leprosy, plague, and smallpox models, associated with different mechanisms of power, namely, sovereign-legal, disciplinary and biopolitical or security apparatuses, respectively. After a presentation of Foucault's contribution, the article seeks to draw an update, continuing the project of an analysis of power. The focus is then directing to the new model of COVID-19 that emerges in the present, marked by the datification of life, the use of big data, the ubiquitous surveillance, and the algorithmic government, within a big
Este é um artigo publicado em acesso aberto (Open Access) sob a licença Creative Commons Attribution, que permite uso, distribuição e reprodução em qualquer meio, sem restrições desde que sem fins comerciais e que o trabalho original seja corretamente citado.

\footnotetext{
${ }^{1}$ Esse texto nasceu de uma apresentação feita no dia 23 de julho de 2020 no Ciclo de Conferências "Filosofia como vírus", do Grupo de Pesquisa O Estado de Exceção no Brasil Contemporâneo, da Faculdade de Direito da Universidade Federal de Minas Gerais. Segue o link de acesso ao vídeo, disponível no Youtube: https://www.youtube.com/watch? $v=J 4$ ymei450Rk\&feature=youtu.be. Agradeço Emanuella Ribeiro Halfeld Maciel pela realização da transcrição. A presente versão foi revista e ligeiramente alterada pelo autor.

2 Professor Adjunto de Teoria e Filosofia do Direito e do Estado da Faculdade de Direito da Universidade Federal de Minas Gerais. Doutor em Filosofia pela UFMG, com estágio de pesquisa na École des Hautes Études en Sciences Sociales (EHESS/Paris). Coordenador do Grupo SIGA (Sociedade da Informação e Governo Algorítmico) e do GFDP (Grupo Filosofia, Direito, Poder).
} 
technocratic dream, of a digitalized society, controlled and managed efficiently.

Keywords: pandemic; Foucault; power; COVID-19 model.

\section{Introdução}

Para tratar do tema proposto neste artigo, Pandemia como laboratório de poder, proponho, primeiro, desenvolver uma reflexão bem geral acerca da experiência pandêmica como uma espécie de momento oportuno para diferentes formas de experimentação e para a emergência de novas tecnologias de poder. Ela age de maneira a aprofundar, articular, reordenar e fazer avançar em uma determinada direção certas práticas de governo, certas estratégias de dominação. $O$ percurso deste texto começa abordando, em termos mais gerais, a questão da oportunidade para novas experiências no campo da política (1). Depois, o foco será direcionado para algumas reflexões desenvolvidas por Michel Foucault na segunda metade dos anos 1970, relacionando a emergência de novas tecnologias de poder ao enfrentamento de doenças, mencionando justamente as experiências de diferentes epidemias ao longo da história (2). Por fim, $\circ$ artigo se concluirá com algumas linhas de atualização, para pensar qual a especificidade desse momento novo que nós vivemos (3).

\section{Política, conflito e oportunidade}

Começando por uma reflexão um pouco mais geral, podemos dizer, voltando aos antigos, que a política é uma espécie de esforço de organização da nossa vida em comum. É uma experiência permanentemente conflituosa, haja vista que sempre existem perspectivas diferentes, concepções conflitantes de como viver ou de como organizar a vida social. Seguindo a concepção apresentada por Foucault no curso $\mathrm{Em}$ defesa da sociedade, proferido no Collège de France em 1976, a experiência política pode ser vista como uma experiência de guerra permanente, na qual existem sempre vencedores $e$ também vencidos.' Existem aqueles que ditam suas leis e aqueles que são oprimidos, aqueles que fazem valer seus valores e aqueles que são silenciados, excluídos e até mesmo eliminados.

Dentro dessa experiência conflituosa que é a construção de uma vida em comum, existe uma noção que os antigos conheciam muito bem: o kairós (kalpós). Por essa noção, entende-se uma espécie de momento oportuno ou uma ocasião propícia para uma determinada ação política, para se investir ou avançar em uma determinada proposta ou direção. O domínio desse timing era, inclusive, considerado uma grande virtude política. Uma habilidade importante daquele que se dedica à política consiste justamente em saber agarrar o kairós, ou seja, saber aproveitar o momento oportuno para poder avançar em suas pretensões.

Nesse sentido, os antigos também aproximavam, e isso é curioso, a arte política da arte médica, porque também no combate às doenças era preciso saber agarrar o kairós, aproveitar o momento oportuno para poder debelar uma doença, para enfrentar adequadamente uma enfermidade. Como se pode ver, os antigos sabiam bem da importância dessa virtude, tanto na arte política,

\footnotetext{
${ }^{1}$ FOUCAULT, Em defesa da sociedade.
} 
quanto na médica. Doença, assim como a vida social, é algo movente, polimorfo, que está em constante transformação. A prática médica ou política deve agir de modo rápido, deve saber agarrar as oportunidades em meio às mudanças. É preciso perceber $\circ$ momento mais oportuno e atacar a doença no momento da crise.

Nesse sentido, é interessante lembrar da figura de Édipo, na peça Édipo rei, de Sófocles. ${ }^{2}$ Toda dinâmica da peça nasce justamente do enfrentamento de uma peste, de uma doença que se abate sobre a cidade de Tebas. Vemos ali, como Foucault analisa nas conferências $A$ verdade e as formas jurídicas (1973), uma resposta de Édipo que é, ao mesmo tempo, terapêutica, de enfrentamento de uma doença, e, também, do domínio da ação política e da investigação de um crime, envolvendo novos procedimentos judiciais. $^{3}$

Pandemia, em suma, parece-me funcionar como um kairós: o momento oportuno, em um certo sentido, para que determinadas estratégias políticas avancem, para que se testem medidas que são emergenciais, que facilmente seriam rejeitadas em outras circunstâncias, mas que, agora, encontram o momento oportuno para que sejam ensaiadas e experimentadas. A ideia, então, é de que a emergência sanitária funciona como um grande laboratório de poder.

A pandemia funciona como laboratório nesse sentido: uma ocasião para se testar algo mais radical, especialmente em um contexto em que certos entraves e dificuldades são amenizados ou retirados. É possível, assim, avançar em tendências que, muitas vezes, já existem, mas que adquirem, no novo contexto, uma situação mais oportuna para que sejam experimentadas de uma maneira mais radical.

Dito isso, gostaria então de colocar algumas perguntas, formuladas em termos bem amplos: qual é a utopia social que encontra agora seu momento oportuno de realização, de experimentação? Afinal de contas, qual sociedade nós estamos sonhando para nós hoje? $O$ que nós estamos dispostos a experimentar? Quais pretensões encontram agora seu kairós, seu momento oportuno para avançar? E quais são os vencedores e os vencidos nesse novo projeto social, para $\circ$ qual talvez estejamos caminhando?

\section{Foucault: enfrentamento de doenças e tecnologias de poder}

Nessa segunda parte deste artigo, gostaria de retomar algumas análises realizadas por Michel Foucault já faz mais de quarenta anos. $O$ exemplo das epidemias é recorrente em seu pensamento, mobilizado justamente para ilustrar momentos nos quais certas formas de funcionamento do poder foram testadas ou ensaiadas. Podemos dizer que esse é um exemplo clássico ou paradigmático de Foucault.

Quando Foucault desenvolve essas análises? A partir de meados dos anos 1970, no seio do projeto de uma analítica do poder, que nada mais é do que um esforço de análise e descrição de como o poder funciona. Não o que é o poder, mas sim como ele opera, como ele funciona, quais são suas táticas, seus instrumentos, seus objetos. Uma descrição propriamente dita das tecnologias de poder. O exemplo, então, da epidemia,

\footnotetext{
2 SÓFOCLES, Édipo rei.

${ }^{3}$ FOUCAULT, A verdade e as formas jurídicas.
} 
aparece com frequência, ilustrando justamente contextos nos quais modos de funcionamento do poder são testados ou postos em prática. Eles ganham terreno e tendem, muitas vezes, a normalizar-se, a adquirir certa hegemonia na sequência.

Esse tipo de análise aparece, diretamente, ao menos em três textos do Foucault. Em Vigiar e punir (1975), no capítulo sobre panoptismo, Foucault contrapõe o "modelo da peste", que exemplifica $\circ$ modo disciplinar de controle social, ao "modelo da lepra", que é visto como uma resposta medieval, de tipo soberano. ${ }^{4}$ Essa questão aparece também no curso intitulado Os anormais, proferido no Collège de France no mesmo ano de publicação do livro Vigiar e punir, no qual Foucault traça a mesma contraposição entre a peste e a lepra na aula de 15 de janeiro de 1975.5 Três anos depois, em Segurança, Território, População, Foucault também retoma essa distinção, incluindo, contudo, logo na primeira aula do curso, proferida no dia 11 de janeiro de 1978, um terceiro tipo de enfrentamento epidêmico: 0 "modelo da varíola". 6 Essa inclusão do modelo da varíola, aliás, é bastante interessante, pois, naquele ano de 1978, Foucault tinha organizado um seminário no Collège de France que contou com a participação da filósofa e médica AnneMarie Moulin, que defenderia posteriormente uma tese sobre a história da varíola e da vacinação.7 Aparentemente, Foucault incorporou isso nos cursos da época.

Primeiro, gostaria de apresentar esses modelos analisados por Foucault para, na sequência, pensar sobre o modelo que vou chamar de "modelo da COVID-19".
Se o modelo da lepra, segundo Foucault, é baseado em mecanismos legais, se o modelo da peste é baseado em dispositivos disciplinares e se 0 modelo da varíola se assenta em dispositivos de segurança, eu diria que o modelo da COVID-19 é baseado em dispositivos informacionais. Mas, antes de avançar sobre isso, precisamos entender melhor a natureza e os modos de funcionamento desses dispositivos de poder.

Realizarei, em primeiro lugar, uma exposição rápida desses modelos pensados por Foucault, começando pela lepra. A lepra é basicamente um modelo baseado na exclusão do leproso, do doente, daquele que é capaz de transmitir alguma doença. É um procedimento medieval que está assentado na ideia de uma grande divisão, na lógica da marcação e na partição binária. É um poder que se exerce sobre um território e fixa uma clara fronteira: os leprosos só podiam circular fora dos domínios da cidade. É uma lógica de exclusão por fechamento: os leprosos são condenados ao banimento. Isso faz nascer uma massa de excluídos e uma série de práticas de rejeição, de separação. A lógica é de separar essas duas grandes massas confusas: de um lado ficam os leprosos, de outro a comunidade purificada. Há, portanto, nesse modelo da lepra, a criação de um lado de fora, de um espaço exterior. Um conjunto de medidas é então tomado, tendo em vista a proteção da cidade, como a edificação de fortificações e de muros, no seio de uma lógica de segregação.

Nesse modelo da lepra são mobilizados mecanismos basicamente jurídicos:

\footnotetext{
${ }^{4}$ FOUCAULT, Vigiar e punir.

${ }^{5}$ FOUCAULT, Os anormais.

${ }^{6}$ FOUCAULT, Segurança, território, população.

${ }^{7}$ MOULIN, Histoire du système immunitaire.
} 
decretos declaravam determinados indivíduos como leprosos e impunham a eles uma série de proibições extremamente severas, que passavam pelas vestimentas, pela obrigatoriedade do uso de um capuz, de uma matraca, para avisar as pessoas da sua aproximação, e de uma condenação à errância fora dos muros da cidade, constituindo uma verdadeira sentença de morte. Tudo isso era acompanhado por uma série de ritos religiosos de despedida, de súplica, todo um conjunto de condenações morais em relação a esses indivíduos acometidos pela doença. Por trás de tudo isso, dessas ações de separação, de segregação e de banimento, Foucault detecta um sonho político, que é o sonho da comunidade pura. Essa é a utopia que movimenta, digamos assim, essas ações.

O segundo modelo analisado por Foucault é o da peste, marcado pela inclusão do pestilento. Ao contrário do leproso, que era excluído, o pestilento não será mais banido da cidade. $O$ doente permanecerá no interior dos domínios da pólis e sob o olhar atento do vigia. É um procedimento moderno, de tipo administrativo, policial, que emerge no século XVIII. Ele não é mais baseado em uma grande divisão, sobre quem está dentro da cidade e quem está fora. $O$ novo modelo é baseado em uma inclusão controlada do pestilento: a lógica da quarentena, na qual cada indivíduo tem - seu devido lugar. Cada um será submetido a uma vigilância e a uma correção individualizada dos desvios cometidos. É um poder que não se exerce mais tendo por objeto privilegiado o território, como era o poder soberano, mas que se exerce sobre os corpos dos indivíduos, conformando um mecanismo claramente disciplinar.
Ao invés da exclusão e do fechamento, temos um controle de circulação no modelo da peste, uma vigilância dos comportamentos. A lógica consiste em evitar aglomerações, confusões, em fazer diferenciações individuais. Ao invés de criar o espaço do fora, como acontecia no modelo da lepra, o enfrentamento da peste vai envolver um espaço mapeado, esquadrinhado, observado permanentemente. Ao invés da fortificação dos grandes muros, temos um panóptico, ou seja, uma estrutura vigilante, um espaço que é todo ele recortado, policiado exaustivamente. $O$ que prevalece não é a opacidade do grande muro medieval, mas a transparência e a individualização em uma estrutura arquitetônica panóptica. Ao invés de instrumentos jurídicos, são mobilizados, sobretudo, mecanismos normalizadores, do tipo disciplinar, como exames, contagens, relatórios, registros minuciosos e fiscalizações incessantes.

Ao invés de os saberes envolvidos serem de tipo religioso, com suas condenações morais, novos saberes disciplinares emergem, assim como novas personagens normalizadoras, como médicos, magistrados e intendentes. $O$ sonho político disciplinar afasta-se da utopia medieval da sociedade pura. Um novo sonho emerge: a sociedade completamente disciplinada, bem treinada, adestrada, dócil e completamente transparente.

Temos ainda, em Foucault, um terceiro modelo: a varíola. Ele não se confunde com a exclusão do leproso, nem a inclusão disciplinar do pestilento. Entra em cena no combate à varíola no século XIX uma nova estratégia: a gestão da epidemia. Qual a lógica desse novo modelo? Trata-se de um procedimento econômico-calculista, de controle social. As técnicas que serão mobilizadas agora 
não são mais jurídicas, nem propriamente disciplinares. São, acima de tudo, técnicas biopolíticas ou securitárias de gestão populacional.

Qual a lógica do combate à varíola? É uma gestão populacional por meio da análise de uma série de acontecimentos prováveis. A doença passa a ser pensada e enfrentada como um fenômeno global, submetida a um cálculo de probabilidades que faz uso de instrumentos estatísticos. Nasce, nesse contexto, uma nova medicina, que é mais preventiva. Emerge também um poder que, ao invés de agir sobre um território, como no combate à lepra, ou sobre os corpos individuais, como na disciplina, é um poder que age sobre um conjunto da população. Estamos, assim, diante de uma lógica biopolítica ou de dispositivos de segurança.

Qual a característica de atuação do modelo da varíola? Uma média do que é considerado ótimo ou aceitável é fixada e age-se no sentido de modular as curvas $e$ as evoluções da contaminação. A estratégia é essa: uma intervenção que visa eliminar as tendências que são vistas como mais desfavoráveis entre as diferentes curvas normais, prováveis. Temos aquilo que Foucault chamou de um jogo das normalidades diferenciais. Age-se dentro das curvas possíveis, para fazer com que se realize a tendência considerada mais benéfica. Em suma, vemos um jogo da normalidade.

Aqui são mobilizados dispositivos securitários, que funcionam por meio de levantamentos estatísticos. É preciso saber quantos contaminados temos, quantos mortos, qual a idade das pessoas que morreram, qual a probabilidade de uma pessoa de determinada idade, sexo, um histórico de doenças anteriores, morrer, qual o risco de sequela etc. É preciso fazer uma série de levantamentos para realizar um cálculo de risco. Os mecanismos mobilizados não são mais os jurídicos, como na lepra, não são mais os disciplinares, como na peste, mas são agora imunitários: práticas de inoculação, de vacinação.

Emerge aqui a noção de "caso". É interessante o uso dessa palavra: "fulano é um caso". A referência a um caso é justamente uma maneira de individualizar um fenômeno coletivo. Algo só é um caso dentro de um fenômeno global. Emerge também a noção de "risco", de "perigo", de "crise" e toda uma lógica de controlar a aceleração do contágio, achatar as curvas. Esse vocabulário aparece claramente no discurso da epidemiologia, nas curvas exponenciais de desenvolvimento de doenças infectocontagiosas, em como controlar essas curvas etc. Estamos, assim, no domínio da gestão populacional. Os novos saberes mobilizados, diferentemente daqueles disciplinares $e$ dos ritos religiosos da lepra, envolvem novas formas de intervenção: estatística, demografia, epidemiologia, economia etc. Novos instrumentos aparecem também, como o cálculo de risco e todo um esforço de normalização, de lidar com as diferentes curvas de normalidade.

E qual o sonho político desse modelo da varíola? Se o combate à lepra era movido pelo ideal da comunidade pura e o enfrentamento da peste tinha por aspiração uma sociedade bem treinada e disciplinada, o sonho do modelo da varíola reside na construção de uma sociedade segura, eficiente, com riscos controlados. Essa fantasia emerge a partir do século XIX, encontrando sua expressão na governamentalidade 
liberal e, posteriormente, na racionalidade neoliberal.

Para finalizar esse ponto, algumas observações importantes. A doença atua, em geral, tanto em termos reais quanto imaginários, como símbolo de uma desordem, de um desarranjo, de uma confusão que faz nascer a necessidade de colocar as coisas no lugar, seja um organismo, como no caso da ação médica, seja a sociedade, no caso da ação política. Por trás dessa vontade de colocar as coisas no lugar, de desfazer aquilo que ficou confuso, vários sonhos políticos são mobilizados. Sonhos de organização social, a utopia de uma sociedade bem ordenada. $\bigcirc$ que verificamos é uma espécie de medo da confusão, de temor do contágio.

Esse medo do contágio pode assumir outras formas, não apenas de uma doença. Os perigos não são necessariamente de ordem sanitária. A lógica securitária estende-se para combater todas as ameaças. Elas podem assumir a forma das revoltas, dos crimes, da vagabundagem, da indisciplina, da errância, da libertinagem, das contracondutas de uma maneira geral. Enfim, tudo aquilo que escapa ou desvia daquilo que consideramos normal ou aceitável constitui uma ameaça. Essa lógica do sonho político não se limita ao enfrentamento epidêmico ou de uma doença.

É em razão de medos variados que prendemos ou que fazemos várias coisas em nome de uma sociedade, em defesa de uma determinada organização social. Fazemos o que exatamente? Encarceramos, excluímos, marginalizamos, banimos, matamos, marcamos pessoas, vigiamos, controlamos, gerimos populações, calculamos riscos e por aí vai. São maneiras diferentes de exercer o poder, de lidar com os perigos inerentes à organização humana, àquilo que é considerado ameaçador a uma determinada ordem, a uma determinada ordenação que consideramos que é melhor para a sociedade. Entram em cena as fantasias políticas. $O$ sonho medieval, por exemplo, é o do grande confinamento: tirar todos os impuros. $O$ sonho disciplinar moderno é o do bom adestramento, de um mundo no qual todos são dóceis, úteis e produtivos. Por fim, temos o sonho neoliberal e securitário, que é o da gestão eficiente de todos os riscos. Temos, assim, diferentes esquemas, mas que não são incompatíveis entre si.

Nesse ponto, gostaria de fazer uma segunda observação. Esses modelos apresentados não se encadeiam na forma de uma mera sucessão: primeiro vem o modelo da lepra, depois o da peste, depois o da varíola. Não se trata de mera sucessão no tempo e Foucault foi bem claro sobre isso em vários momentos. Esses modelos se articulam entre si. Os dispositivos de segurança, por exemplo, envolvem uma inflação legal, ou seja, mecanismos jurídicos, assim como técnicas de vigilância de natureza disciplinar. Esses mecanismos não são eliminados, eles são rearticulados no interior de uma estratégia hegemônica de tipo securitária. Um modelo não toma simplesmente o lugar do outro, não sucede ou passa a existir em seu lugar. O que muda é o sistema de correlação entre os diferentes modos de funcionamento de poder, ou seja, determinadas técnicas ganham terreno, se rearticulam e tendem a adquirir certa hegemonia, mas sem excluir os outros modos de funcionamento do poder. Para ilustrar isso, cito uma passagem do curso Segurança, Território e População: "A segurança é uma maneira de acrescentar, de colocar em 
funcionamento, para além dos mecanismos propriamente securitários, as velhas armaduras da lei e da disciplina". 8

\section{O modelo da COVID-19}

Na última parte deste artigo, gostaria de refletir sobre o novo modelo da COVID19 à luz, obviamente, desse esforço que Foucault já fez de tentar pensar os modos de funcionamento do poder a partir da modernidade. Minha pretensão, portanto, é dar continuidade a esse projeto de uma analítica do poder, traçando uma linha de atualização. Meu olhar será, então, direcionado para o nosso tempo.

Qual a natureza do novo modelo da COVID-19? Se o modelo da lepra era soberano/jurídico, o da peste disciplinar e o da varíola securitário, podemos dizer que aquilo que está em jogo no enfrentamento da COVID-19 é uma espécie de datificação da vida. Como podemos compreender isso? Gostaria de fazer referência a quatro textos, recentes, que também estão pensando o enfrentamento da COVID-19 na mesma linha proposta aqui, ou seja, partindo das análises realizadas por Foucault e procurando pensar a experiência contemporânea.

primeiro texto que gostaria de fazer referência intitula-se Aprendiendo del virus, do filósofo espanhol Paul Preciado, publicado no jornal El País em 28 de março de 2020 e incluído no livro intitulado Sopa de Wuhan. 9 Considero esse um texto bastante interessante, que me influenciou a pensar algumas questões atuais. Ele parte de Foucault, justamente dessas análises apresentadas anteriormente neste artigo, afirmando que a epidemia radicaliza e desloca as técnicas biopolíticas:

As epidemias, por seu chamamento ao estado de exceção e pela inflexível imposição de medidas extremas, são também grandes laboratórios de inovação social, a ocasião de uma reconfiguração em grande escala das técnicas do corpo e das tecnologias de poder. 10

Importante destacar que o filósofo espanhol está falando também de uma ocasião, de uma oportunidade para um "laboratório de inovação social" e de técnicas de controle social. Preciado descreve essas mudanças em curso como uma marcha em direção a uma sociedade que será descrita como ciberoral, digital, imaterial e fármacopornográfica. Cito:

A extensão planetária da internet, a
generalização do uso de tecnologias
informáticas móveis, o uso de inteligência
artificial e de algoritmos na análise de big
data, o intercâmbio de informação em grande
velocidade e o desenvolvimento de
dispositivos globais de vigilância informática
através de satélites são índices desta nova
gestão semiótico-técnica digital. Se as
chamamos de pornográficas é, em primeiro
lugar, porque essas técnicas de biovigilância
se introduzem dentro do corpo, atravessam a
pele e nos penetram, e, em segundo lugar,
porque os dispositivos de biocontrole não
funcionam mais através da repressão [...], mas
através da incitação ao consumo e à
produção constante de um prazer regulado e
quantificável. ${ }^{11}$

Quanto mais consumimos e quanto mais saudáveis somos, mais facilmente somos controlados. Preciado percebe, também, que $\circ$ enfrentamento da COVID-19 envolve tecnologias distintas, medidas que são disciplinares junto com outros tipos de medida. Preciado compara, inclusive, o enfrentamento feito na Ásia e na Europa, como ilustrações de

\footnotetext{
${ }^{8}$ FOUCAULT, Segurança, território, população, p. 12.

${ }^{9}$ PRECIADO, Aprendiendo del virus.

${ }^{10}$ PRECIADO, Aprendiendo del virus, pp. 175-176, tradução nossa.

11 PRECIADO, Aprendiendo del virus, p. 172, tradução nossa.
} 
estratégias diferentes de enfrentamento da COVID-19.

Em suma, também Preciado vê nesse período que estamos vivendo hoje, nessa crise sanitária, o momento oportuno, o kairós para a emergência de uma nova utopia de comunidade imune e uma nova forma de controle. Ele está atento para essas questões e termina seu texto com um chamamento à resistência, propondo um grande blecaute: desligar os celulares e desconectar-se da internet.

O segundo texto que gostaria de fazer referência, mais rapidamente, foi redigido pelo filósofo sul-coreano radicado na Alemanha Byung Chul-Han e publicado também no jornal El País no dia 21 de março de 2020. ${ }^{12}$ Nesse texto, Han defende que a psicopolítica digital estaria sendo acompanhada de uma biopolítica digital, por um controle mais próximo do corpo, envolvendo dados biométricos como a temperatura corporal e o nível de açúcar no sangue. Han chamará esse fenômeno de "digitalização da vida". Ele percebe também a existência de uma diferença nas formas de enfrentamento da pandemia nos países asiáticos e na Europa, destacando que no oriente percebe-se um modelo mais apoiado no uso de big data. Nesse sentido, Han cita - CoronaApp, que é um aplicativo utilizado na Coreia do Sul para rastrear e conhecer, com bastante detalhe, com quem uma pessoa infectada se aproximou, com quem teve contato etc. Nesse texto, Han parece-me ambíguo, pois, por um lado, mostra-se mais simpático ao modelo asiático, que é visto como mais eficiente do que o fechamento de fronteira realizado na Europa, considerado uma técnica ultrapassada e ineficiente. Mas, por outro lado, Han percebe que, em função da comoção causada pelo vírus, corremos o risco de levar para a Europa um regime policial e digital do tipo chinês. Apesar de louvar - modelo oriental de enfrentamento da COVID-19, Han, aparentemente, reconhece que devemos ficar atentos a esse risco.

O terceiro texto, que na verdade é uma apresentação, mais exatamente uma live ou um web-débat, refere-se a uma intervenção da filósofa do direito belga Antoinette Rouvroy no dia 12 de julho de 2020, tratando do tema da vigilância digital e das liberdades fundamentais. ${ }^{13}$ Rouvroy aponta para o fato de que vemos hoje uma nova maneira de cartografar o fenômeno epidêmico, que é mais móvel e mais desterritorializada, diferente das formas de esquadrinhamento panóptico, como vemos no modelo da peste analisado por Foucault. Rouvroy reconhece que nós temos ainda muita dificuldade para descrever esse novo modelo emergente, que tendemos a ser muito maladroit, ou seja, desastrado, estabanado, como se não encontrássemos as palavras certas ou precisas para descrever o que está acontecendo.

O último texto que gostaria de fazer referência é de um filósofo brasileiro chamado Rone Eleandro Santos, intitulado Epidemia, controle e vigilância: das quarentenas analógicas à quarentena digital, publicado em julho de 2020 na revista Voluntas. ${ }^{14}$ Rone tenta justamente descrever essa quarentena digital como uma nova forma de enfrentamento epidêmico, que ele compara com as formas que Foucault analisou previamente. $O$ texto não analisa $\circ$

\footnotetext{
12 HAN, O coronavírus de hoje e o mundo amanhã.

13 WEB-DÉBAT..., s/p.

${ }^{14}$ SANTOS, Epidemia, controle e vigilância.
} 
modelo da varíola, limitando-se à peste e à lepra. Rone ressalta, nessa quarentena digital, a emergência de um modelo baseado na hiperconexão do infectado, envolvendo monitoramento, rastreamento e registro de dados.

Para finalizar, gostaria de deixar algumas questões claras. Meu ponto principal é que o modelo da COVID-19, que é marcado por essa datificação da vida, implica em um rearranjo das formas tradicionais de poder. Todas elas permanecem de alguma forma. Nós temos algo do modelo de exclusão do leproso, por exemplo, no isolamento, na construção de zonas seguras, no fechamento de fronteiras, na deportação e no distanciamento social. Há algo do sonho da comunidade pura em jogo. Além disso, remobilizamos também o modelo disciplinar da peste, através do controle da circulação, da vigilância permanente, dos registros minuciosos. Há também algo da ordem de uma sociedade bem treinada, adestrada. Além disso, reativamos também o modelo da varíola, da gestão populacional, com - achatamento da curva, as análises das tendências de desenvolvimento epidemiológico, os cálculos de risco, os jogos de normalidades diferenciais. Há todo um sonho de uma sociedade bem gerida, com riscos controlados.

Mas verificamos também algumas novidades. Essas novidades se dão, em grande medida, em função das novas tecnologias disponíveis de rastreamento, como o CoronaApp na Coreia do Sul, e a vigilância subcutânea (under skin surveillance), como a vigilância dos dados biométricos. Por trás disso, um novo sonho parece emergir, um sonho de viés tecnocrático, a utopia de uma sociedade da informação, governada por algoritmos.

Nós conjugamos, portanto, diferentes estratégias políticas. Algumas dessas estratégias são mais negativas, no sentido de proibitivas, impositivas. Já outras são mais constitutivas, produtivas, positivas. Quais são as nossas ações mais claramente negativas? Aquelas das quais emerge um poder claramente autoritário, com uma lógica de saída da democracia, de uma vigilância que é da ordem banóptica, para usar um termo cunhado por Didier Bigo para descrever a exclusão ou banimento misturada com uma estrutura panóptica. ${ }^{15}$

Há uma lógica também necropolítica, um poder de morte, de eliminação, mobilizado por um novo tipo de racismo, de exclusão daqueles que são considerados indesejáveis. Tem algo dessa ordem, mas temos também uma lógica mais positiva do funcionamento de poder, no sentido de constitutiva. Nesse sentido, temos uma espécie de poder mais insidioso, mais invisível, que é o poder dos algoritmos, a lógica de uma governamentalidade algorítmica, a instauração de uma vigilância mais imperceptível e eficiente, a partir da extração de dados e do uso de big data. Temos aqui uma produção biopolítica misturada com a lógica do sujeito empreendedor de si mesmo, a lógica do coach, do fitness, do sujeito-empresa, tudo isso também está em jogo nesse novo modo de funcionamento do poder.

\section{Considerações finais}

Em suma: qual o novo sonho político contemporâneo que está aparecendo? Qual a utopia social que está mais visível agora, que está sendo testada, que está

\footnotetext{
15 BIGO, Security, exception, ban and surveillance.
} 
sendo experimentada no enfrentamento da COVID-19? Parece-me que é um sonho tecnocrático, um sonho de modelização digital da realidade, a utopia de colocar tudo em dados. Um sonho de controle biométrico, sistemático, total. Um sonho de uma humanidade completamente transparente para si mesma, que acredita que se libertou dos mistérios e que agora tudo ficará transparente, tudo será conhecido em seus mínimos detalhes e eficientemente gerido. Uma utopia social que emerge, portanto, de uma sociedade digitalizada, visível, registrada, segura, confortável. Sonhamos em ser conduzidos para o sucesso, em termos uma direção eficiente de nossas condutas que promete eliminar aquilo que é indesejável, inoportuno, que prejudica a reprodução do capital.

Há uma tensão aqui, que Foucault já havia percebido no curso Nascimento da biopolítica (1979), ao descrever a racionalidade de governo liberal e neoliberal. ${ }^{16}$ Trata-se da tensão inerente a ela, entre liberdade, entendida como liberdade de mercado ou de concorrência, e segurança, do Estado de controle social ou Estado policial. Nós temos um Estado que produz uma determinada liberdade, que é a liberdade de empreender, de buscar vencer na vida em um mundo concorrencial e desigual, mas, ao lado disso, para garantir essa mesma "liberdade", nós temos um aparato policial: a vigilância disciplinar, o controle biopolítico, a cultura do perigo, a eliminação dos indesejáveis, a necropolítica. Infelizmente, é esse o tipo de sociedade que parece estar sendo sonhada hoje: um projeto social que encontra na pandemia o seu kairós, o momento oportuno para avançar e tornar-se hegemônico.

Precisamos, é claro, lutar contra o vírus, esse é o desafio imediato. E precisamos fazer isso com as melhores armas que temos, em cair em obscurantismo ou saídas milagrosas. Apesar disso, não podemos deixar que o controle da epidemia implique em um controle permanente de nossas vidas. Não podemos ignorar $\circ$ risco de normalizarmos a exceção. Não podemos ver o controle de nossas vidas, corpos e comportamentos como um ideal de organização social, como um remédio para outras doenças e outros desvios.

Esse é, talvez, o grande desafio de nosso tempo. Um desafio duplo: não apenas lutar contra o vírus, mas lutar também contra um projeto social que vai encontrar agora um ambiente propício para crescer e se normalizar. Trata-se de um projeto de viés autoritário e feição neoliberal, que irá encontrar na emergência sanitária e na manipulação de antigos e poderosos temores um terreno propício para avançar. Esse me parece um risco a também ser levado a sério nesse contexto.

\footnotetext{
${ }^{16}$ FOUCAULT, Nascimento da biopolítica.
} 
Referências

BIGO, Didier. Security, exception, ban and surveillance. In: LYON, David (ed.). Theorizing surveillance: the panopticon and beyond. Cullompton, Portland: Willan, pp. 46-68.

FOUCAULT, Michel. Os anormais: curso no Collège de France (1974-1975). Trad. Eduardo Brandão. São Paulo: Martins Fontes, 2001.

FOUCAULT, Michel. A verdade e as formas jurídicas. Trad. Roberto Machado e Eduardo Morais. $3^{a}$ ed. Rio de Janeiro: NAU, 2003.

FOUCAULT, Michel. Em defesa da sociedade: curso no Collège de France (1975-1976). Trad. Maria Ermantina Galvão. São Paulo: Martins Fontes, 2005.

FOUCAULT, Michel. Segurança, território, população: curso dado no Collège de France (1977-1978). Trad. Eduardo Brandão. São Paulo: Martins Fontes, 2008.

FOUCAULT, Michel. Nascimento da biopolítica: curso dado no Collège de France (1978-1979). Trad. Eduardo Brandão. São Paulo: Martins Fontes, 2008.

FOUCAULT, Michel. Vigiar e punir: nascimento da prisão. $36^{a}$ ed. Trad. Raquel Ramalhete. Petrópolis: Vozes, 2009.

HAN, Byung-Chul. O coronavírus de hoje e $\circ$ mundo amanhã, segundo o filósofo Byung-Chul Han. El País, 2020. Disponível em:

https://brasil.elpais.com/ideas/202003-22/o-coronavirus-de-hoje-e-omundo-de-amanha-segundo-o-filosofo- byung-chul-han.html. Acesso em: 23 jul. 2020.

MOULIN, Anne-Marie. Histoire du système immunitaire: immunologie et médicine (1880-1984). Tese de Doutorado em Filosofia. Orientação de François Dagognet. Université Lyon 3, 1986.

PRECIADO, Paul. Aprendiendo del virus. In: AMADEO, Pablo (ed.). Sopa de Wuhan: pensamiento contemporáneo en tiempos de pandemias. ASPO, 2020, pp. 163-185. Disponível em: http://tiempodecrisis.org/wpcontent/uploads/2020/03/Sopa-deWuhan-ASPO.pdf?fbclid=IwAR386959_q7FG9ZCeGsEFSxGBOerZNNMf3s $1 \mathrm{~h}$ mLn8nYjcieT4QA-yyx6zE. Acesso em: 23 jul. 2020.

SANTOS, Rone Eleandro. Epidemia, controle e vigilância: das quarentenas analógicas à quarentena digital. Voluntas Revista internacional de Filosofia, Santa Maria, v. 11, Ed. Especial, 2020. Disponível em: https://periodicos.ufsm.br/voluntas/artic le/view/43837. Acesso em: 23 jul. 2020.

SÓFOCLES. Édipo rei. Trad. Trajano Vieira. São Paulo: Perspectiva, 2004.

WEB-DEBAT (partie 3): surveillance numerique et libertes fondamentales. Jean-Marc Desmet - MED-ICS, 12 jul. 2020. 1 vídeo (23:16 min). Publicado por Jean-Marc Desmet - MED-ICS. D. Disponível em: https: //www.youtube.com/watch? $v=7 \times 1$ IV27bv8s. Acesso em 23 jul. 2020.

Recebido em: 26.08.2020

Aprovado em: 23.01.2021 